\title{
Formação superior rizomática: flexibilidade curricular proposta pela UFABC
}

\author{
Allan Moreira Xavier ${ }^{1}$ \\ Leonardo José Steil ${ }^{1}$
}

\section{Resumo}

Ainda que o currículo do bacharelado em ciência e tecnologia (BC\&T) da Universidade Federal do $\mathrm{ABC}$ (UFABC) apresente uma proposta flexível de formação superior, tal flexibilidade passa, quando de sua execução, por um conjunto de fatores limitadores cujo estabelecimento reaproximam a proposta de um currículo tradicional. Compreender como funcionam os agenciamentos nos quais está circunscrito o curso a partir da identificação de aspectos que o aproximam de um currículo rizomático, assim como das linhas de fuga molarizantes desse projeto formativo, resume o principal objetivo deste artigo. Para tanto, realizou-se um levantamento arqueológico dos discursos a partir de entrevistas semiestruturadas acerca da execução do projeto original e documentos oficiais, incluindo as revisões dos projetos pedagógicos do BC\&T da UFABC, e normativas que regulam a execução do curso na universidade. A concomitância das trajetórias formativas entre os cursos de formação interdisciplinar e cursos de formação específica, a carga horária elevada em unidades curriculares de escolha dos alunos e a ausência de pré-requisitos permitiriam ao aluno singularizar sua formação, escapando à unidade curricular pretendida nas tradicionais grades curriculares. Tais possibilidades de compreensão rizomática desse currículo esbarram nas formações tradicionais dos docentes e nas opções de gestão tradicional do currículo, que empurram o projeto no sentido de uma formação tradicional e positivista.

\section{Palavras-chave}

Currículo - Rizoma - Ensino superior - Flexibilidade curricular.

\section{Rhizomatic Higher Education: curricular flexibility proposed by UFABC}

Even though the curriculum of the bachelor's degree in science and technology (BC\&T) by the Federal University of $A B C(U F A B C)$ presents a flexible proposal for higher education,

\footnotetext{
1- Universidade Federal do ABC, Santo André, SP, Brasil.
} Contatos: allan.xavier@ufabc.edu.br e steil@ufabc.edu.br 
such flexibility changes, when the project is carried out, by a set of limiting factors whose implementation makes it very similar to a traditional curriculum. The main objective of this article can be summarized to understanding the agencies the course is circumscribed within by identifying the aspects that make it closer to the rhizomatic curriculum as well as the molar lines of escape of this formative project. Therefore, an archaeological survey of the discourses was conducted based on semi-structured interviews focusing on performing the original project and on official documents, including the revisions of the original pedagogical project for $B C \& T$ and regulations affecting the course in the university. The concomitance of the interdisciplinary formative itineraries and specific professional training, the high number of class hours in curricular units chosen by the students and the absence of prerequisites altogether allowed the students to single out their education, avoiding the curricular unit desired in the traditional curricular grids. Such possibilities for a rhizomatic comprehension of the curriculum proposed by UFABC come into conflict with the traditional teacher education and into the options for a traditional management of the curriculum, which push the pedagogical project towards a traditional and positivist formation.

\section{Keywords}

Curriculum - Rhizome - Higher education - Curricular flexibility.

\section{Introdução}

Propostas de reformulação do ensino superior brasileiro não são novas. A Universidade de São Paulo (USP), a Universidade de Brasília (UnB) e a Universidade Estadual de Campinas (Unicamp) surgiram todas como projetos de ruptura com o sistema brasileiro de ensino superior. No entanto, conforme afirma Castilho (2008, p. 95), a implementação das três universidades enfrentou problemas de inversão de precedência, na medida em que a universidade deixava de ser pensada como instituição de estudo para ser organizada como escola profissional e instituição de ensino, além de enfrentar problemas para unificação, dado que todas foram instituídas pela incorporação de escolas profissionais já existentes em suas cidades que negavam o caráter integrativo da universidade. 0 autor argumenta ainda que a universidade brasileira historicamente não se afastou da concepção eclesiástica de universidade portuguesa, fazendo com que sua implantação no Brasil resultasse em instituições com características - ensinismo, profissionismo, isolacionismo, privatismo, autodidatismo e substituismo - que negam a universidade moderna orientada pela pesquisa (CASTILHO, 2008, p. 42), como é o caso do modelo alemão de universidade.

Santos (1995, p. 17-22) avaliou as universidades no fim do século XX e identificou três crises pelas quais elas passavam à época: (a) crise de hegemonia, relativa à contradição das funções tradicionais e atribuídas no decorrer de sua história; (b) crise de legitimidade, 
referente ao descompasso entre a especialização hierarquizada dos conhecimentos e as exigências sociais por políticas de acesso democrático; (c) e crise institucional, resultante da contradição entre autonomia para determinar missões e valores e a pressão para submeter-se a critérios de produtividade e eficácia empresariais.

Passados quinze anos, o sociólogo reavalia (SANTOS, 2008, p. 22-40) a situação das universidades para constatar que a globalização neoliberal da economia aprofundou a crise das universidades, atuando na descapitalização das universidades públicas, na transnacionalização do mercado universitário, na dicotomia entre conhecimento universitário e pluriversitário - como Santos (2008, p. 35-36) denomina o novo modelo de conhecimento contextual, organizado pela aplicabilidade, transdisciplinar e interacionista típico da pós-modernidade. Como alternativa, o autor propõe o desenvolvimento de uma globalização contra-hegemônica da universidade:

As reformas nacionais da universidade pública devem refletir um projeto de país centrado em escolhas políticas que qualifiquem a inserção do país em contextos de produção e de distribuição de conhecimentos cada vez mais transnacionalizados e cada vez mais polarizados entre processos contraditórios. (SANTOS, 2008, p. 41).

Chaui (2003) avalia que a fragmentação que o capitalismo produz nas esferas sociais alterou o caráter universitário de instituição social para prestadora de serviços. Essa visão organizacional e operacional da universidade está atravessada por enunciados que a apresentam dentro de uma sociedade do conhecimento que atua numa nova esfera educativa, a da formação continuada (CHAUI, 2003, p. 8) e que se justificam pela compressão espaço-tempo a que estão submetidas as sociedades pós-modernas. A autora propõe alguns pontos que poderiam guiar a mudança da universidade para uma perspectiva formativa e democrática: posicionamento contra a exclusão social defendendo a formação superior como direito do cidadão; defesa da autonomia universitária mais pela possibilidade de estabelecer seus próprios programas de ensino, pesquisa e extensão e menos pelo caráter administrativo; desfazer a confusão entre massificação e democratização da educação superior partindo de reforma da educação básica; revalorização da docência e da pesquisa, a partir de políticas públicas que recusem os critérios de avaliação de produtividade meramente quantitativos; e tomada de uma postura crítica sobre as ideias de sociedade do conhecimento e educação permanente.

No âmbito do ensino superior brasileiro, a Universidade Federal do ABC (UFABC, 2015b) estabeleceu um novo cenário para a proposição de cursos de formação superior, cujas características eram baseadas em currículos flexíveis e interdisciplinares. Os bacharelados interdisciplinares (BIs) representam uma alternativa de aproximação da educação superior brasileira aos modelos de educação superior vigentes no hemisfério norte, reunindo numa única modalidade de ensino um conjunto de características requeridas pela sociedade para a formação profissional e cidadã ao partir de alguns pressupostos (ALMEIDA FILHO, 2008, p. 155):

- ampliação de conhecimentos e competências cognitivas obtidas por meio de um alargamento de experiências durante a graduação; 
- flexibilização curricular garantida pelo aumento do número de créditos em unidades curriculares optativos;

- ênfase na integração de conhecimentos disciplinares;

- adiamento de escolhas profissionais precoces;

- redução das taxas de evasão.

O bacharelado em ciência e tecnologia (BCET) da UFABC é um BI que, conforme os referenciais orientadores (CNE, 2011), se constitui como um programa de formação em nível de graduação que conduz a diploma, com foco na interdisciplinaridade, no diálogo entre as áreas do conhecimento e na flexibilidade curricular. Ao priorizar em sua estrutura curricular arranjos interdisciplinares que consideram as correlações entre a realidade sociocultural e ambiental em que se insere, o projeto pedagógico de curso (PPC) do BC\&T (UFABC, 2015a) ressalta, por sua vez, a importância de uma formação integral nas ciências, incluindo a visão histórica da nossa civilização e privilegiando a capacidade de inserção social no sentido amplo.

Ao aluno, a flexibilidade curricular é apresentada como uma liberdade de escolha e definição de sua própria trajetória acadêmica, que deve ser cumprida dentro dos prazos de integralização definidos pela resolução ConsEPE n 166 (UFABC, 2013). Essa liberdade é garantida pela categorização das unidades curriculares na UFABC, discriminadas como obrigatórias, de opção-limitada e de livre escolha, sendo as duas últimas de completa escolha do aluno e representando aproximadamente metade da carga horária prevista para integralização no curso. Além disso, o acesso às unidades curriculares na UFABC não é regrado pelos tradicionais pré-requisitos: são apresentadas no catálogo anual (UFABC, 2012a) as recomendações de conhecimentos fundamentais para pleno entendimento e aproveitamento da unidade curricular em questão. A inexistência de pré-requisitos possibilita aos alunos o exercício da sua autonomia nos momentos de matrícula (UFABC, 2015a, p. 12) e a reorganização de suas trajetórias quando de imprevistos e mudanças de perfil formativo.

Diante desse novo panorama, a intenção deste trabalho - produto de pesquisa em nível de doutorado - é avaliar os enunciados clamados ao redor da ideia de flexibilidade curricular, assim como as principais características desse projeto curricular que estabeleceu novos critérios tanto para a expansão de universidades federais (BRASIL, 2007) quanto para a criação de tantas outras (CNE, 2011). Para compreender melhor esse cenário, por meio de uma pesquisa qualitativa, foram realizadas análises de discurso na perspectiva foucaultina (FOUCAULT, 2013; FISCHER, 2012) de entrevistas semiestruturadas com docentes (identificados LD1 e LD2), gestores (identificados G1 e G2), idealizador do projeto (identificado ID) e alunos (identificados LA1, LA2, LA3, LA4), e de documentos legais e normativos da universidade. As entrevistas foram realizadas na própria UFABC, entre os meses de março e junho de 2014, após aprovação da pesquisa no Comitê de Ética e Pesquisa da UFABC. Todas as entrevistas foram gravadas e transcritas, e os sujeitos entrevistados concordaram com as transcrições autorizando seu uso mediante assinatura do Termo de Consentimento Livre e Esclarecido. Os gestores ocuparam cargos na coordenação do BC\&T e na pró-reitoria de graduação da UFABC em tempos distintos, sendo ambos também docentes credenciados no curso. 
Este trabalho trata de analisar as consequências da flexibilidação curricular proposta a partir da confluência de fatores (instituição jovem, formada por doutores, inserida em um contexto de mobilidade e expansão, criada a partir de cursos interdisciplinares) que indicam a UFABC um ambiente satisfatório para inovação curricular. Tais análises serão construídas utilizando como ponto de partida o referencial teórico elaborado pela parceria entre Gilles Deleuze e Félix Guattari. Nesse intuito, o artigo apresentará na próxima seção alguns aspectos relativos às compreensões de currículo e as possibilidades de elaboração e implementação de um currículo rizomático, a partir de uma perspectiva pós-estruturalista para educação superior. Na seção Currículo-revolução? será questionada a concepção de inovação curricular autoproclamada no projeto da universidade, enquanto no item Currículo-dois-por-um serão discutidas as relações entre as formações no curso interdisciplinar e no curso específico da apresentação cartesiana do currículo, e em Currículo-diferenciado serão identificados aspectos limitadores para a implementação e execução desse projeto de formação.

\section{Currículo}

Amorim (2004, p. 153), a partir de uma perspectiva pós-estruturalista, imagina o currículo como uma narrativa em acontecimentos e, ao mesmo tempo, como celebração de modos de ver e estar no mundo. Como produção de individuações pela comunicação intrinsicamente pedagógica dos signos que podem se tornarem simbólicos e convencionais, o autor se posiciona contrariamente ao modelo prescritivo de trajetória de aprendizagem baseada em ordenação de conteúdo.

Ao abandonar uma definição de currículo, mas buscar pela sua intencionalidade, Corazza (2001, p. 9) concebe-o como uma linguagem, na qual podem ser identificados significantes, significados, conceitos, posições discursivas, ironias e fluxos. 0 discurso curricular fornece apenas uma das tantas maneiras de formular, interpretar e atribuir sentidos ao mundo, mas sua sintaxe e semântica têm função constitutiva daquilo que enuncia, corporificando instituições, saberes, normas, prescrições, regulamentos, programas, valores e modos de subjetivação (CORAZZA, 2001, p. 10).

Pensando o currículo a partir de uma estrutura rizomática, Roy (2003) preocupa-se com a construção de novas conexões que nos permitam liberar-nos de uma falsa escravidão das relações lineares e, mesmo que momentaneamente, produzir multiplicidades. A estética rizomática carrega potencialidades, pois permite dimensionar os processos educativos em uma teia de interrelações movimentada por mecanismos de resistências, aceitação, rupturas, manutenções e subjetivações (AMORIM, 2004, p. 157).

Conforme pontua Gallo (2008), a aplicação do conceito de rizoma na organização curricular substituiria um acesso arquivístico estanque ao conhecimento por um infinito trânsito entre os saberes. Ações interdisciplinares intensificam trânsitos verticais e horizontais, mas não avançam de fato no fim da compartimentalização enquanto uma perspectiva rizomática reconhece a multiplicidade das áreas do conhecimento, rompendo com as hierarquizações e disciplinarizações. Um currículo rizomático passaria: (a) pelo abandono da pretensão cientificista da educação, esta tornar-se-ia produção singular 
a partir de múltiplos referenciais cujo resultado não se vislumbraria de antemão; (b) pelo abandono da pretensão massificante do processo educativo, permitindo formações subjetivas autônomas; e (c) pelo abandono da pretensão de compreensão da realidade pela justaposição de unidades multifacetadas (GALL0, 2008, p. 80-81).

Uma educação rizomática, por sua vez, abre-se para a multiplicidade, para uma realidade fragmentada e múltipla, sem a necessidade mítica de recuperar uma ligação, uma unidade perdida. Os campos do saber são tomados como absolutamente abertos; com horizontes, mas sem fronteiras, permitindo trânsitos inusitados e insuspeitados. (GALLO, 2008, p. 81).

Assim, o currículo não deve ser compreendido como um dado, nem uma interpretação ou co-construção, mas pensado como um devir-currículo (ROY, 2003), um esforço para liberar as intensidades presas nos significantes. Tal transformação em uma recusa de estruturas fechadas, estratificadas, nas quais a diferença se confina, direciona a um estado de abertura a movimentos de pura diferença. A análise curricular proposta neste trabalho deixa de questionar as representações embutidas nos enunciados curriculares, mas passa a interrogar como funcionam tais agenciamentos maquínicos curriculares.

\section{Currículo-diferenciado}

Pacheco (2008) distingue duas viabilidades de inovação curricular possibilitadas por reformas na educação portuguesa: a diversificação e a diferenciação curriculares. Esta representa alterações essencialmente nos aspectos metodológicos e avaliativos do currículo, partindo do pressuposto de que todos os alunos têm o mesmo percurso a seguir, mas precisam de diferentes caminhos para atingir os objetivos educativos. Aquela designa formas organizacionais do currículo que permitem ao aluno ser confrontado com caminhos curriculares distintos, seja possibilitando prosseguimento de estudos, seja por escolhas profissionais.

Você pode sempre se surpreender e mudar, às vezes até a área. É valido que você se decida antes, mas aqui você tem a oportunidade de ver as diferentes áreas e você pode descobrir alguma que você pode gostar mais. (LA4, 2014, entrevista concedida ao pesquisador).

A possibilidade de os alunos determinarem suas trajetórias - permitida pelo currículo da UFABC nas unidades curriculares de opção-limitada e livre-escolha - e de mudarem suas trajetórias - essencialmente experimentando unidades curriculares livres nas áreas que lhe interessem -, garantiria ao currículo da UFABC a liberdade necessária para que seja entendido como um currículo diversificado. Mas, partindo dessa carcaterização, é possível compreender como funcionam os agenciamentos que conferem a esse currículo a concretização de fluxos e desejos singulares, o que permite pensá-lo como um currículo-acontecimento?

Não se pode ingenuamente esquecer que esta liberdade custa à universidade, no limite, uma condição em que os currículos dos alunos tornem-se tão individualizados quanto possível. A fala de G2 traz referência à manutenção dos subsídios necessários aos objetivos a que a universidade foi proposta. 
Parece-me que qualquer instituição tem que saber aonde ela que quer chegar e fomentar esses objetivos. Ela tem que dar subsídios. Parece-me desconfortável colocar todos os professores no ambiente e deixá-los que escolham um caminho confortável. Então, parece que aí está o papel da instituição em ajudar, fomentar, dar subsídios. (G2, 2014, entrevista concedida ao pesquisador).

Pacheco (2008) salienta que, para efetivação plena da diversificação curricular, alguns aspectos da gestão do currículo devem ser cuidados:

Existência de uma liderança curricular que promova a coordenação horizontal ou a integração das atividades de ensino-aprendizagem pertencentes a uma turma ou a um departamento e/ou conselho de grupo disciplinar; o agrupamento flexivel dos alunos; a conjugação do trabalho do professor com os serviços de apoio pedagógico especializado com vista ao sucesso educativo do aluno; a articulação dos recursos e materiais curriculares; a construção de um projeto educativo de escola, inserida numa comunidade ou território educativo. (PACHECO, 2008, p. 182; grifos nossos).

G2 marca a necessidade de lideranças assumirem o papel de coordenação das atividades docentes, direcionadas no sentido do menor esforço, para execução do projeto educativo ao qual a UFABC se propôs. G1 destaca ainda que a universidade estabeleceu critérios de organização dos alunos em turmas para resolver processos burocráticos institucionais (como matrícula, ocupação de salas etc.), escolha não mais adequada, em concordância com Pacheco (2008):

O conceito de turma não consegue casar com o conceito de liberdade. É um princípio completamente diferente. (G1, 2014, entrevista concedida ao pesquisador).

Além dos cursos interdisciplinares, a UFABC também oferece cursos em áreas específicas do conhecimento (UFABC, 2010), vinculados aos interdisciplinares. A formação do estudante estabelecida pelo Projeto Pedagógico Institucional - PPI/UFABC (UFABC, 2006) e pelo PPC do BC\&T em vigor (UFABC, 2015a) caracteriza as unidades curriculares em três categorias distintas (UFABC, 2012b): obrigatórias, de opção-limitada e de livre escolha.

0 projeto original era um terço de disciplinas obrigatórias que eram a cara da UFABC. Um terço de disciplinas de opção-limitada em que o aluno ia decidir qual perfil de bacharel em ciência e tecnologia teria, um conjunto de disciplinas para exercer as escolhas dele, mas escolhas direcionadas. E um terço de disciplinas livres. Na época, livre era livre. Ele queria fazer teatro na USP e aprender a falar, ele ia fazer. Ele é dono do futuro dele. (G1, 2014, entrevista concedida ao pesquisador).

Essa liberdade proposta no projeto original da UFABC e o exercício da liberdade pelo aluno e pela universidade permitem que a formação na UFABC seja entendida como uma série de encontros, tendo em vista que a alocação de turmas a docentes e a matrícula dos alunos nas mesmas não são traçadas a partir de uma história linear curricular, mas como consequência de desejos e escolhas de trajetórias singulares, produzindo realidades curriculares individualizadas: 
As multiplicidades são a própria realidade, e não supõem nenhuma unidade, não entram em nenhuma totalidade e tampouco remetem a um sujeito. [...] Os princípios característicos das multiplicidades concernem a seus elementos, que são singularidades; a suas relações, que são devires; a seus acontecimentos, que são hecceidades (quer dizer, individuações sem sujeito); a seus espaços-tempos, que são espaços e tempos livres; a seu modelo de realização, que é o rizoma (por oposição ao modelo da árvore); a seu plano de composição, que constitui platôs (zonas de intensidade contínua); aos vetores que as atravessam, e que constituem territórios e graus de desterritorialização. (DELEUZE; GUATTARI, 2011, p. 10).

Idealmente, deve-se permitir que a economia do desejo escape ao máximo à política de sobrecodificação do capitalismo, ao mesmo tempo suportando seu modo de funcionamento sem traumas. Não se trata de negar, de contornar os fluxos descodificados do capitalismo, mas dar-lhes lugar próprio, e, dentro do possível, governá-los. Conclui Guattari (1985, p. 55) que se trata de criar condições que permitam aos indivíduos adquirir meios de expressão relativamente autônomos e relativamente não recuperáveis pelas tecnologias de formação do poder.

A individualização do desejo, o agrupamento de indivíduos, é a operação da produção de subjetividade capitalística, que instaura fenômenos de serialização, de identificação, que se prestam à manipulação pelos equipamentos capitalísticos. Nesse processo, a singularidade perde todo acúmulo processual possível. Deve-se, entretanto, estabelecer uma pragmática da produção de desejo, que, quando esmagadora, atinge não só o indivíduo, mas o grupo (GUATTARI; ROLNIK, 2013, p. 280).

Sobre essa flexibilização curricular e as multiplicidades que pode gerar, podemos contar com as análises de Ó (2013) de entrevistas concedidas por Michel Foucault ao jornal Le Monde, afirmando que este acreditava ser necessário modificar a formação recebida pela universidade, de tal maneira que esta permitisse "ao indivíduo modificar-se ao seu gosto" (FOUCAULT apud Ó, 2013, p. 32). Também a estrutura hierárquica da universidade foi contestada por Foucault, que negava a necessidade do modelo francês tradicional de formação universitária e a submissão permanente à informação. "Não é uma questão de modelo, todos os modelos são molares: é preciso determinar as moléculas e as partículas em relação às quais as vizinhanças engendram-se e se defınem" (DELEUZE e GUATTARI, 2012, p. 85). A essas estratificações profissionais opõem-se microagenciamentos analítico-militantes suscetíveis de se cristalizar em torno de uma classe, uma escola, uma universidade (GUATTARI, 1985, p. 67):

Uma revolução, em qualquer domínio que seja, passa por uma libertação prévia de uma energia do desejo. E manifestadamente, só uma reação em cadeia, atravessando as estratificações existentes, poderá catalisar um processo irreversível de questionamento das formações de poder às quais está amarrada a sociedade atual (GUATTARI, 1985, p. 67-68).

\section{Curriculo-dois-por-um}

A proposição curricular da UFABC de formação por ciclos (e sua execução) composta por formação generalista e formação profissional específica foi questionada 
por Marchelli (2007), que entende a formação na UFABC de forma hierárquica, do curso interdisciplinar inicialmente para o curso de formação específica a posteriori caracterizando os ciclos de formação sequenciais. Tal questionamento põe em xeque a formação recebida pelos alunos, e declara que o

[...] planejamento curricular suscitado pelo projeto pedagógico estabelece uma ordenação hierárquica cujos resultados finais pretendidos são colocados no início, o que parece afrontar todas as teorias do ensino. (MARCHELLI, 2007, p. 11).

0 autor defende - a partir de sua compreensão de interdisciplinaridade - que a essência interdisciplinar está sendo pensada de maneira inversa na UFABC: os alunos não poderão prescindir de um elevado nível conhecimento (nível interdisciplinar) das ciências tradicionais logo de seu ingresso no ensino superior. A compreensão de que a formação na UFABC se dá por ciclos sequenciais também é compartilhada pela docente LD1:

Eu faço uma brincadeira, logo no começo. Na primeira aula eu pergunto: "Que curso que você está fazendo?” E a grande maioria responde engenharia. Poucos são os químicos, ou físicos, ou biólogos, que a gente sabe. E aí eu digo: "Você está enganado, você está aqui para fazer o BC\&TT, o que você fizer depois do BC\&T é outra coisa”. É um curso que a gente pode até dizer que é complementar. (LD1, 2014, entrevista concedida ao pesquisador).

Todavia, consideramos errônea a compreensão de que os BIs da UFABC estabelecem seus cursos em ciclos sequenciais, pois indica uma compreensão linear positivista dos processos de formação. Isso porque a formação interdisciplinar se dá simultaneamente à formação específica, garantidas na liberdade de escolha das trajetórias curriculares, pelas diferentes categorias das unidades curriculares que compõem os cursos e pela ausência de pré-requisitos. Os enunciados das falas de docentes e discentes evidenciam o estabelecimento de relações progressivas, lineares e causais, talvez marcando os limites de execução do projeto, cujos executores - docentes e gestores - têm os discursos curriculares tradicionais e reproduzem em seus alunos compreensões errôneas ou limítrofes das possibilidades formativas na UFABC.

Vale ressaltar o antagonismo estabelecido na literatura e na fala da docente entre os cursos de formação generalista (interdisciplinar) e de formação específica (profissional), assim como o forte discurso profissionalizante a que estão submetidos os cursos de formação superior no Brasil. Esse forte direcionamento utilitarista da educação superior, evidencia um antagonismo entre teoria e prática (e, consequentemente, uma racionalidade especializante, arborescente e binária das experiências formativas), assim como se deu na implantação dos primeiros cursos de nível superior no Brasil (ALMEIDA FILHO, 2008; CASTILHO, 2008), entre os cursos superiores e os cursos de profissionais liberais.

As unidades curriculares de opção-limitada e de livre escolha são ofertadas pelos cursos de graduação de formação específica da UFABC (UFABC, 2012b), assim, os alunos cursam, concomitantemente, aquelas previstas nos cursos de formação interdisciplinar e as dos de formação específıca. Assim, reitera-se posição tomada 
na hipótese de que as escolhas dos alunos, ao corresponderem a aproximadamente metade da carga horária do BC\&T (UFABC, 2015a) e ciente de que a oferta dessas unidades curriculares parte das coordenações dos cursos específicos, há concomitância de formação, não subordinação hierárquica.

Entretanto, como já apontado acima, os pontos de territorialização curricular encontram-se especialmente nos desejos de unificação e controle do currículo, tendo um caminho frutífero na tradição de organização e execução curricular: a própria formação disciplinar dos docentes e gestores. A resolução ConsEPE n 139 (UFABC, 2012b) estabelece um conflito com a resolução ConsEPE no 102 (UFABC, 2011), já que esta determina um conjunto de disciplinas de opção-limitada para cada curso enquanto aquela determina que as disciplinas de opção-limitada dos BIs são todas aquelas obrigatórias aos cursos de formação específica. A inclusão de todas as unidades curriculares obrigatórias de cursos específicos na categoria de opção-limitada inclui nesse grupo unidades curriculares de caráter altamente técnico e específico (esperadas em currículos de formação profissional). Em favor de uma maior flexibilidade do currículo as unidades curriculares de opçãolimitada parecem contraditórias: o projeto original permite escolha dos alunos, mas entre um conjunto limitado de unidades curriculares; as normativas mais recentes aumentam o número de unidades curriculares desse conjunto, mas como consequência, reforçam trajetórias curriculares dos cursos de formação específica, retirando do BC\&T parte de sua originalidade - a de curso de formação generalista concomitante ao curso de formação profissional.

\section{Currículo-revolução?}

Os Subsidios para a reforma da educação superior (ABC, 2004) proclamam urgência da reforma do ensino superior no Brasil a qual, segundo acreditam, salvaria a universidade. Anterior aos Subsídios e com forte apelo para a mobilidade de profissionais pelo território da União Europeia (UE), a Declaração de Bolonha (THE EUROPEAN..., 1999), redigida pelo conjunto de ministros da educação que enfrentavam o desafio do processo de unificação continental (ainda) em andamento, objetiva maior comparabilidade e compatibilidade entre os sistemas de ensino superior europeus. A Declaração promove a adoção de um sistema de créditos equivalentes entre as universidades da UE como forma de sustentabilidade de oferta de cursos e de mobilidade dos estudantes, pesquisadores, professores e equipe administrativa entre as instituições, assim como o aproveitamento de conhecimentos adquiridos fora da universidade. Orienta também que a qualidade do ensino garantir-seia pela cooperação no desenvolvimento de critérios e metodologias compatíveis, assim como no desenvolvimento curricular e no desenvolvimento de programas de estudo, treinamento e pesquisa em programas de mobilidade interinstitucionais.

Ao comparar o PPI/UFABC (2006) com os documentos referenciais da Declaração (1999) e dos Subsídios (2004), a proposta, precursora de um novo modelo de educação superior brasileiro, tenta resolver uma demanda local por uma instituição pública de educação superior, mas, principalmente, atende também às demandas contemporâneas nacionais e internacionais por uma reforma radical do ensino superior. Não se pode 
interpretar a sigla UFABC apenas nos sentidos local ou global, quando a intenção é colocar-se em contínua relação com ambos.

0 sistema de formação em dois ciclos proposto na Declaração difere, no entanto, do proposto nos Subsídios, já que o segundo ciclo europeu deve conduzir aos títulos de mestre e doutor - o primeiro de caráter profissionalizante e o segundo, para formação do pesquisador -, enquanto o nacional, aos títulos de atuação profissional (bacharel e licenciado) ou aos títulos de mestre e doutor. Esta é uma das críticas de Almeida Filho (2008, p. 112) ao (não) modelo brasileiro de educação superior, resquícios do Parecer Sucupira de 1968 (MARTINS, 2009): a formação profissional que leva aos mesmos graus do BI, e o mestrado como curso preparatório para formação do doutor.

0 PPI/UFABC é autoproclamado inovador dado que parte de uma compreensão sistêmica e flexível dos problemas do mundo moderno: a universidade pretende formar profissionais que intervenham no sistema produtivo e acadêmico avaliando diversos fatores que, articulados, produzem respostas aos novos problemas da sociedade. Alguns "elementos de impacto" (UFABC, 2006, p. 9) delineiam o projeto e diferenciam-na das universidades brasileiras que existiam até então: (a) mobilidade profissional; (b) oferta de novas formações profissionais interdisciplinares ainda não regulamentadas; (c) educação inicial e continuada organizada por projetos curriculares flexíveis e atualizados; (d) ênfase curricular no conhecimento científico; (e) incentivo ao desenvolvimento empreendedor. Encontramos nesses pilares discursos previamente apresentados tanto na Declaração quanto nos Subsídios, apontando para uma compreensão universalizante do entendimento da razão da universidade no século XXI. Questionando-se sobre a função da universidade na formação contemporânea, ID pondera:

0 que se faz em matéria de ensino na universidade hoje? Exatamente o que se fazia há 50 anos. Então, alguma coisa está errada. Não é possível que você tenha a evolução de conhecimento progredindo em um sentido e a formação universitária completamente estagnada. É preciso que haja o quê? Uma apresentação do conhecimento científico de outra forma. (ID, 2014, entrevista concedida ao pesquisador).

Sibilia (2012), ao questionar o funcionamento do dispositivo escolar na pósmodernidade, indica que a universidade precedeu a genealogia escolar. No entanto, esses "santuários do saber universal" (SIBILIA, 2012, p. 33) também se modernizam quando é preciso, convertendo-se de instituições originalmente eclesiásticas em instituições disciplinares comparáveis às escolas. A autora salienta que as disputas travadas nos âmbitos educacionais durante o século XX demoliram certezas e asperezas disciplinares conquistando a fusão dos aspectos laborais e ociosos.

0 circuito produtivo contemporâneo busca características antes combatidas, como a originalidade associada a certa espontaneidade inventiva, além da capacidade de mudar com rapidez, reciclando o que se é em veloz sintonia com tendências globais. Também se valorizam a livre iniciativa, a motivação, o perfil empreendedor, e a vocação proativa, como atitudes capazes de mover os mercados e gerar benefícios [...] Tudo isso se dá numa cultura que enaltece a busca da celebridade e o sucesso 
imediato, combinando nesse projeto a realização pessoal e a satisfação instantânea, exaltando valores como a autoestima, a aparência juvenil e o gozo constante. (SIBILIA, 2012, p. 48-49).

Como ficaria então o projeto moderno-sólido de educação para a vida toda? 0 projeto moderno fazia da instituição escolar indústria educacional, e dos sujeitos (fixos, centrados), seus produtos acabados (ALMEIDA; GOMES; BRACHT, 2009, p. 64). A passagem para a pós-modernidade faz com que a imutabilidade do mundo e da natureza humana - pressupostos educacionais que permitiram a transmissão do conhecimento e a posição superior do professor na hierarquia educacional - se quebre em diversos fragmentos desconexos, cujas fronteiras o mundo do lado de fora das escolas fez crescer de maneira diferente do que a evolução do dispositivo escolar. Dessa maneira, nos tempos líquidos, a obsessão pela durabilidade e pela ordem é substituída pela transitoriedade e pelo consumismo. "A formação é impensável de qualquer outra forma que não seja uma reformação permanente e eternamente inconclusa”, afirmam Almeida, Gomes e Bracht (2009, p. 66). Nesse cenário, deixam-se de lado as formações de conhecimentos e hábitos bem definidos, aqueles cuja experiência ao longo do tempo poderia oferecer uma vantagem, em detrimento dos projetos de formação flexíveis, numa constante atualização do estado da arte da informação profissional.

A universidade, enquanto templo do saber, precedeu amplamente a instituição escolar. $\mathrm{Na}$ sua vertente europeia, cujas bases instauraram as universidades brasileiras (CASTILHO, 2008), os vínculos com conventos e catedrais são evidentes inclusive na arquitetura dos claustros mais tradicionais, mantendo ecos eclesiásticos que impregnam o vocabulário e elitismo sectário que persistem em suas práticas e rituais (SIBILIA, 2012, p. 33). A universidade também se tornou instituição disciplinar, por consequência. A nova universidade (ALMEIDA FILHO, 2008) deve permitir ir além das finalidades e responsabilidades da universidade tradicional, cujo modelo falido deixa-a em crise permanente. ID acredita no direcionamento mais aberto de ideias:

A universidade, no fundo, tem medo de encontrar um caminho diferente e arriscado. Na realidade, a universidade deve formar pessoas que deveriam dizer: "Eu quero testar as minhas próprias ideias!". "Porque não pode ser desse outro modo que eu proponho?" Eu tenho essa liberdade. E se você não pensar assim, fica com essa terrível limitação: "Eu não sei fazer outra coisa”. 0 que tem de mais importante na formação de doutorado é isso, independência intelectual. (ID, 2014, entrevista concedida ao pesquisador).

Ao avaliar as consequências da instalação das sociedades de controle no regime escolar, Deleuze (2013) antecipa que, nas instituições educacionais, as formas de controle tornam-se contínuas, em especial as avaliações; as ações de formação permanente agem pela escola e sobre ela; os programas de pesquisa das universidades são abandonados com introdução da lógica de mercado em todos os níveis de ensino.

Hardt e Negri (2014, p. 104) argumentam que a instituição educativa deve ser balizada por três princípios que permitam o advento do homem comum: tornar comuns os recursos, desenvolver planos de autogestão e sujeitar as decisões a procedimentos de 
participação democrática. Tomando por base a ideia de que o conhecimento é o bem comum da educação e de que o processo educativo não é meramente uma questão de obtenção de conhecimento, mas de desenvolvimento e exercício de nosso poder de pensar, os autores defendem que o nível mais básico da educação é o autodidatismo produzido em instituições que propiciam relacionamentos (o que não exclui as figuras dos professores e das escolas) orientados para a condução de estudos. "A educação, por conseguinte, é sempre um exercício e uma demonstração em relação à igualdade de singularidades do comum" (HARDT; NEGRI, 2014, p. 105), isto é, ao estudar, reconhece-se a inteligência dos outros e aprende-se beneficiando-se dela.

Tais ideias concordam com as de Deleuze (2013) e de Santos (2008), ao avaliar que as instituições de ensino, principalmente superior, tornaram-se cada vez mais empresariais e dirigidas pelo mercado já que perderam, no último século, grande parte do seu financiamento estatal - que as tornavam públicas e autônomas. Para estabelecerem-se como instituições do comum, os interesses da sociedade como um todo devem guiar os objetivos e pesquisas das universidades. Como o capitalismo em rede abocanhou inclusive a inventividade, a vitalidade, a iniciativa, a intimidade do homem comum com sua capacidade conexionista, talvez a fala de Foucault (2014, p. 9-10) no prefácio de 0 Anti-Édipo, de Gilles Deleuze e Félix Guattari (2011), possibilite os caminhos, como aponta o autor, para uma vida não fascista: liberar a ação política de toda forma de paranoia unitária e totalizante; fazer crescer a ação, o pensamento e os desejos por proliferação, justaposição e disjunção, mais do que por subdivisão e hierarquização piramidal; livrar-se das velhas categorias do negativo, preferindo o que é positivo e múltiplo, a diferença à uniformidade; os fluxos às unidades, as organizações móveis aos sistemas; abandonar a ideia de que a militância é triste, já que o elo entre desejo e realidade é que possui força revolucionária; utilizar a prática política como intensificador do pensamento; desindividualizar pela multiplicação e pelo deslocamento; e não apaixonar-se pelo poder. Não apaixonar-se pelo poder que um currículo fechado, programático, linear, unitário e hierárquico possa garantir às instituições e àqueles que as servem, liberando as incertezas e suspeitas, como defende ID:

E eu citava muitos exemplos [...] como Einstein que dizia: A criatividade é mais importante que o conhecimento". Vai repetir isso no meio acadêmico, as pessoas ficam falando com desconfiança. Mas a imaginação é mais importante que o conhecimento [...] Você não pode ficar exclusivamente na esteira do conhecimento, como se só aquilo que está na esteira é que vale. Se você sai um pouquinho, pronto, ai já não vale mais. Abre-se um abismo de suspeitas. (ID, 2014, entrevista concedida ao pesquisador).

Compreendendo que no currículo proposto pela UFABC, a flexibilidade curricular atua como agenciamento de desejos, abrindo o projeto a multiplicidades de agenciamentos possíveis, caminhamos no sentido do que propõe Gauthier (2002): que se abandone a busca por uma essência real do currículo para que se experimente o/com o currículo, fazendo-o entrar em novos agenciamentos sem conformá-lo em uma definição prévia. Opor as concepções de currículo como corpo, como ser, como objeto, por aquelas de 
superfície, de devir, de obra aberta. A partir de então, conceber o currículo como máquina: que não para de produzir e que é produzida por suas produções. Que não para de efetuar novas ligações, nem por isso, fixando-se. Abrir-se para a criação de currículos, currículos nomádicos, que se dão na escala do tempo dos acontecimentos, rizomatizam-se e escapam a quaisquer territorializações.

\section{Conclusões}

No que se refere ao currículo proposto para o bacharelado em ciência e tecnologia da UFABC, a proposta autoproclamada inovadora da instituição garante formação concomitante generalista e específica através dos dispositivos de liberdade de escolhas curriculares, de categorização de disciplinas e ausência de pré-requisitos formais. Tais características permitem à UFABC cumprir diferentes missões: garantir a formação profissional e expandir a formação generalista. Entretanto, a efeito colateral da flexibilidade proposta pelo currículo é a produção de currículos-acontecimento, de processos de singularização curriculares que escapam às territorializações formativas. Defendemos essa perspectiva em função de uma leitura linear e sequencial das vivências curriculares propiciadas pelos BIs da UFABC, principalmente porque as liberdades de escolha dos alunos na construção de seus percursos aliam-se a composição do currículo entre unidades curriculares interdisciplinares e de formação profissional especifica concomitantemente.

Esse efeito colateral é territorializado por agenciamentos de significação determinados por normativas que, a uma primeira leitura, aumentam as possibilidades de escolha, mas, atentamente, formalizam trajetórias enrijecidas de formação. Percebe-se, assim, uma coexistência de possibilidades de um currículo intensidade, rizoma, singular, fugidio, generoso: o currículo-diagramático, em seu devir-molecular permitiria ao aluno singularizar sua formação, escapando à unidade curricular pretendida nas tradicionais grades curriculares. Entretanto, as possibilidades de exercer um currículo rizomático esbarram nas compreensões cartesianas de organização curricular, manifestadas nas análises desse currículo na literatura e na formação tradicional dos docentes que executam o projeto e nas trajetórias enrijecidas institucionalizadas em normativas marcadas por discursos epistemológicos tradicionais que estratificam o currículo: currículo-programático, em devir-molar.

Apostamos que as linhas de fuga a tais processos de molarização das experiências curriculares, de territorialização das singularidades, encontrem-se no investimento de possibilidades de criação curricular: partir de saberes, conceitos e territórios conhecidos para produzir, a cada encontro propiciado pela formação flexível na UFABC, novos percursos em nomadismo permanente.

\section{Referências}

ABC. ACADEMIA BRASILEIRA DE CIÊNCIAS. Subsídios para a reforma da educação superior. Rio de Janeiro: ABC, 2009. Disponível em: <http://www.abc.org.br//MG/pdf/doc-6680.pdf>. Acesso em: 20 out. 2014. 
ALMEIDA, Felipe Quintão de; GOMES, Ivan Marcelo; BRACHT, Valter. Bauman \& a educação. Belo Horizonte: Autêntica, 2009.

ALMEIDA FILHO, Naomar de. Universidade nova no Brasil. In: SANTOS, Boaventura de Souza; ALMEIDA FILHO, Naomar de. A universidade no século XXI: para uma universidade nova. Coimbra: Almedina, 2008. p. 107-260.

AMORIM, Antônio Calor Rodrigues de. Os roteiros em ação: multiplicidades na produção de conhecimentos escolares. In: LOPES, Alice Casimiro; MACEDO, Elizabeth Macedo (Org.). Currículo de ciência em debate. Campinas: Papirus, 2004. p. 153-192.

BASTOS, Carmen C. B. C. 0 processo de Bolonha no espaço europeu e a reforma universitária brasileira. Educação Temática Digital, Campinas, v. 9, n. esp., p. 95-106, dez. 2007.

BRASIL. Decreto ${ }^{\circ}$ 6.096, de 24 de abril de 2007. Institui o Programa de Apoio a Planos de Reestruturação e Expansão das Universidades Federais - REUNI. Disponível em: <http://www.planalto.gov.br/ccivil_03/_ ato2007-2010/2007/decreto/d6096.htm >. Acesso em: 15 jul. 2014.

CASTILHO, Fausto. 0 conceito de universidade no projeto da UNICAMP. Campinas: UNICAMP, 2008.

CHAUl, Marilena. A universidade pública sobre outra perspectiva. Revista Brasileira de Educação, Rio de Janeiro, n. 24, p. 5-15, 2003.

CNE/BRASIL. Parecer CNE/CES nº 266/2011, aprovado em 5 de julho de 2011 - Referenciais orientadores para os bacharelados interdisciplinares e similares das universidades federais. Disponível em: <http://portal. mec.gov.br/index.php?option=com_content\&view=article\&id=17649:referenciais-orientadores-para-osbacharelados-interdisciplinares-e-similares-\&catid=323:orgaos-vinculados>. Acesso em : 15 jul. 2014.

CORAZZA, Sandra Mara. 0 que quer um currículo? Pesquisas pós-críticas em educação. 3. ed. Petrópolis: Vozes, 2001.

DELEUZE, Gilles. Conversações. 3. ed. Rio de Janeiro: Ed. 34, 2013.

DELEUZE, Gilles; GUATTARI, Félix. 0 anti-Édipo: capitalismo e esquizofrenia 1. 2. ed. Rio de Janeiro: Editora $34,2011$.

DELEUZE, Gilles; GUATTARI, Félix. Mil platôs: capitalismo e esquizofrenia 2. v. 4. 2. ed. Rio de Janeiro: Editora 34, 2012.

FISCHER, Rosa Maria Bueno. Trabalhar com Foucault. Belo Horizonte: Autêntica, 2012.

FOUCAULT, Michel. A arqueologia do Saber. 8. ed. Rio de Janeiro: Forense Universitária, 2013.

FOUCAULT, Michel. Ditos e escritos: genealogia da ética, subjetividade e sexualidade. v. 9. Rio de Janeiro: Forense Universitária, 2014. 
Allan Moreira XAVIER; Leonardo José STEIL

GALLO, Sílvio. Deleuze \& a educação. 2. ed. Belo Horizonte: Autêntica, 2008.

GAUTHIER, Clermont. Esquizoanálise do currículo. Educação \& Realidade, Porto Alegre, v. 27, n. 2 , p. 143-155, 2002.

GO0DSON, Ivor F. Currículo: teoria e história. Petrópolis: Vozes, 2013.

GUATTARI, Félix. Revolução molecular: pulsações políticas do desejo. 2. ed. São Paulo: Brasiliense, 1985.

GUATTARI, Félix; ROLNIK, Suely. Micropolítica: cartografias do desejo. 12. ed. Petrópolis: Vozes, 2013.

HARDT, Michael; NEGRI, Antonio. Declaração: isto não é um manifesto. São Paulo: N-1, 2014.

MARTINS, Carlos Benedito. A reforma universitária de 1968 e a abertura para o ensino superior privado no Brasil. Educação \& Sociedade, Campinas, v. 30, n. 106, p. 15-35, 2009.

MARCHELLI, Paulo S. O novo projeto universitário no Brasil e o foco no currículo interdisciplinar. e-Curriculum, São Paulo, v. 3, n. 1, p.1-20, dez. 2007.

Ó, Jorge Ramos do. Foucault e o problema da escrita: uma introdução. In: CLARETO, Sônia Maria; FERRARI, Anderson (Org.). Foucault, Deleuze \& educação. 2. ed. Juiz de Fora: UFJF, 2013. p. 21-62.

PACHECO, José Augusto. Currículo: teoria e práxis. Porto: Editora Porto, 2001.

PACHECO, José Augusto. Estudos curriculares. São Paulo: Cortez, 2005.

PACHECO, José Augusto. Notas sobre diversificação/diferenciação curricular em Portugal. Intermeio, Campo Grande, v. 14, n. 28, p. 178-187, jul./dez. 2008.

ROY, Kaustuv. Teachers in nomadic spaces: Deleuze and curriculum. New York: Peter Lang, 2003.

SACRISTÁN, Jose Gimeno. 0 currículo: uma reflexão sobre a prática. Porto Alegre: Artmed, 2000.

SANTOS, Boaventura de Souza. Pela mão de Alice: 0 social e o político na pós-modernidade. São Paulo: Cortez, 1995.

SANTOS, Boaventura de Souza. A universidade no século XXI: para uma reforma democrática e emancipatória da universidade. In: SANTOS, Boaventura de Souza; ALMEIDA FILHO, Naomar de. A universidade no século XXI: para uma universidade nova. Coimbra: Almedina, 2008. p. 13-106.

SIBILIA, Paula. Redes ou paredes: a escola em tempos de dispersão. Rio de Janeiro: Contraponto, 2012.

THE EUROPEAN HIGHER EDUCATION AREA. The Bologna Declaration. [S. I: s. n.]. 1999. Disponível em: <http:// www.ufabc.edu.br/images/stories/pdfs/declaracaodebolonhaingles.pdf>. Acesso em: 01 ago. 2014.

UFABC. Catálogo de disciplinas de graduação. Santo André: UFABC, 2012a. Disponível em: <http://prograd. ufabc.edu.br/images/pdf/catalogo_de_disciplinas_2012.pdf>. Acesso em: 2 nov. 2014. 
UFABC. Projeto pedagógico da Universidade Federal do ABC. Santo André: UFABC, 2006. Disponível em: <http:// www.ufabc.edu.br/images/stories/pdfs/institucional/projetopedagogico.pdf>. Acesso em: 15 jul. 2014.

UFABC. Projeto pedagógico do bacharelado em ciência e tecnologia. Santo André: UFABC, 2015a. Disponível em: <http://www.ufabc.edu.br/images/stories/pdfs/administracao/ConsEP/anexo-resolucao-188-revisaodo-ppc-bct-2015.pdf>. Acesso em: 15 out. 2015.

UFABC. Resolução ConsEPE $n^{\circ}$ 074, de 16 de agosto de 2010. Define as composições e atribuições das coordenações dos bacharelados interdisciplinares e dos cursos de formação específica. Santo André: UFABC, 2010. Disponível em: <http://www.ufabc.edu.br/index.php?option=com_content\&view=article\&id =3859\%3Aresolucao-consep-no-74-160810-define-as-composicoes-e-atribuicoes-das-coordenacoesdos-bacharelados-interdisciplinares-e-dos-cursos-de-formacao-especifica\&catid=427\%3Aconseperesolucoes\&ltemid=280 > . Acesso em: 30 out. 2014.

UFABC. Resolução ConsEPE n 102, de 31 de março de 2011. Substitui a Resolução ConsEPE nº62 que regulamenta o processo de convalidação de disciplinas do bacharelado em ciência e tecnologia. Santo André: UFABC, 2011. Disponível em: <http://www.ufabc.edu.br/index.php?option=com_cont ent\&view=article\&id=4859\%3Aresolucao-consep-no-102-150311-substitui-a-resolucao-consepno-62-que-regulamenta-o-processo-de-convalidacao-de-disciplinas-do-bacharelado-em-ciencia-etecnologia\&catid=427\%3Aconsepe-resolucoes\&ltemid=42>. Acesso em: 30 out. 2014.

UFABC. Resolução ConsEPE $n^{\circ}$ 166. Revoga e substitui a Resolução ConsEP nº 44 e normatiza o desligamento dos alunos por decurso dos prazos máximos para progressão e integralização nos cursos de graduação, 2013. Santo André: UFABC, 2013. Disponível em: <http://prograd.ufabc.edu.br/images/pdf/resolucao_ consepe_166.pdf>. Acesso em: 15 jul. 2014.

UFABC. Resolução da Comissão de Graduação $n^{0}$ 002, de 20 de março de 2012. Substitui a resolução $C G n^{0}$ 01/2010, estabelecendo normas e procedimentos para credenciamento e descredenciamento dos docentes nos cursos de graduação da UFABC. Santo André: UFABC, 2012b. Disponível em: <http:// prograd.ufabc.edu.br/doc/res_cg_02_2012_credenciamento_descredenciamento.pdf>. Acesso em: 30 out. 2014.

UFABC. UFABC atinge excelentes colocações em recentes rankings universitários. Santo André: UFABC, 2015b. Disponível em: <http://www.ufabc.edu.br/index.php?option=com_content\&view=article\&id=93 30:ufabc-atinge-excelentes-colocacoes-em-recentes-rankings-universitarios\&catid=731: noticias\&ltem id=183 > . Acesso em: 15 out. 2015.

Recebido em: 31.10 .2016 Revisões em: 07.03.2017 Aprovado em: 21.03.2017

Allan Moreira Xavier é professor adjunto do Centro de Ciências Naturais e Humanas da Universidade Federal do ABC (UFABC). Licenciado e bacharel em química pela Universidade Estadual de Campinas (Unicamp), mestre em nanociências e materiais avançados e doutor em ciência e tecnologia, com tese defendida na área de educação química, ambos pela Universidade Federal do ABC. 
Leonardo José Steil é professor adjunto do Centro de Ciências Naturais e Humanas da Universidade Federal do ABC (UFABC). Bacharel em química pela Fundação Universidade Regional de Blumenau, mestre em química pela Universidade Federal de Santa Catarina e doutor em química pela Universidade Estadual de Campinas (Unicamp), onde também realizou estágio pós-doutoral. 